\title{
Child-Like Adults: Dual-Task Effects on Collective vs. Distributive Sentence Interpretations
}

\author{
Anna M. B. de Koster $^{1 *}$, Petra Hendriks ${ }^{1}$ and Jennifer K. Spenader ${ }^{2}$ \\ ${ }^{1}$ Center for Language and Cognition Groningen (CLCG), Faculty of Arts, University of Groningen, Groningen, Netherlands, \\ ${ }^{2}$ Department of Artificial Intelligence, Faculty of Science and Engineering, University of Groningen, Groningen, Netherlands
}

\section{OPEN ACCESS}

Edited by:

Valentina Cuccio,

University of Messina, Italy

Reviewed by: Stephen Politzer-Ahles,

Hong Kong Polytechnic

University, China

Xiaoming Jiang,

McGill University, Canada Xiaolin Zhou,

Peking University, China

${ }^{*}$ Correspondence:

Anna M. B. de Koster a.m.b.de.koster@rug.nl

Specialty section:

This article was submitted to

Language Sciences,

a section of the journal

Frontiers in Psychology

Received: 27 April 2020

Accepted: 05 May 2021

Published: 10 June 2021

Citation:

de Koster AMB, Hendriks $P$ and Spenader JK (2021) Child-Like Adults:

Dual-Task Effects on Collective vs. Distributive Sentence Interpretations.

Front. Psychol. 12:556120.

doi: 10.3389/fpsyg.2021.556120
In this work, we consider a recent proposal that claims that the preferred interpretation of sentences containing definite plural expressions, such as "The boys are building a snowman," is not determined by semantic composition but is pragmatically derived via an implicature. Plural expressions can express that each member of a group acts individually (distributive interpretation) or that the group acts together (collective interpretation). While adults prefer collective interpretations for sentences that are not explicitly marked for distributivity by the distributive marker each, children do not show this preference. One explanation is that the adult collective preference for definite plurals arises due to a conversational implicature. If implicature calculation requires memory resources, children may fail to calculate the implicature due to memory limitations. This study investigated whether loading Dutch-speaking adults' working memory, using a dual task, would elicit more child-like distributive interpretations, as would be predicted by the implicature account. We found that loading WM in adults did lead to response patterns more similar to children. We discuss whether our results offer a plausible explanation for children's development of an understanding of distributivity and how our results relate to recent debates on the role of cognitive resources in implicature calculation.

Keywords: conversational implicature, distributivity, dual task, language development, pragmatics, quantification, semantics, working memory

\section{INTRODUCTION}

An essential feature of language is the ability to refer to groups of individuals. We can talk about these individuals performing actions individually, or together as a group. Consider sentence (1), which contains the plural definite description the boys:

(1) The boys are building a snowman.

Sentences with plural definite subjects like (1) are compatible with more than one interpretation according to semantic theories (e.g., Landman, 2000; Champollion, 2017). Are the boys in sentence (1) building one snowman together (the collective interpretation, see Figure 1)? Or are they building individual snowmen (the distributive interpretation, see Figure 2)? A collective interpretation simply requires that the predicate applies to the set denoted by the plural expression. For example, in a situation with three boys, $\mathrm{Al}$, Ben, and Chris, the collective interpretation of the sentence "Every boy is building a snowman" means that several of the boys are building one snowman together. The distributive interpretation, on the other hand, requires that the predicate applies to each member of the set denoted by the plural expression individually. This would 


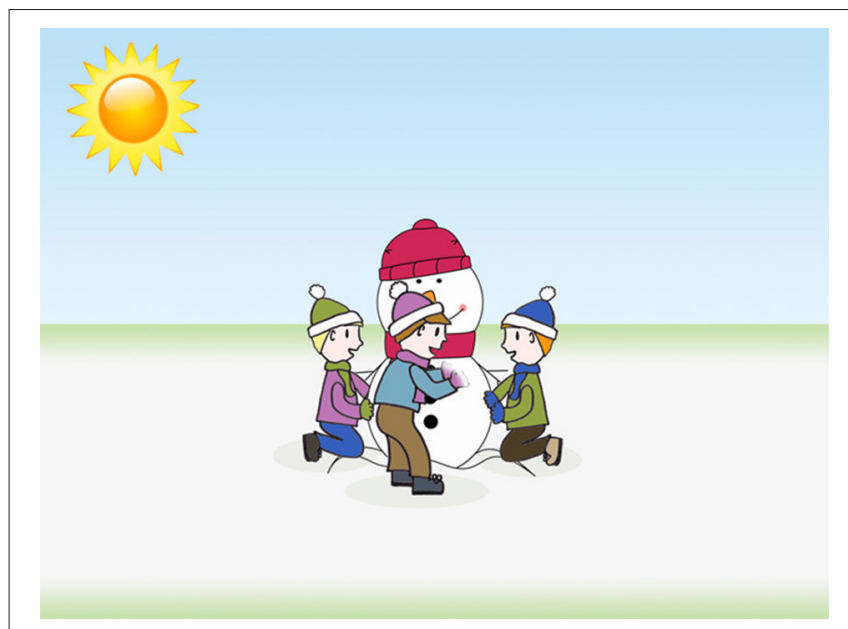

FIGURE 1 | Collective interpretation.

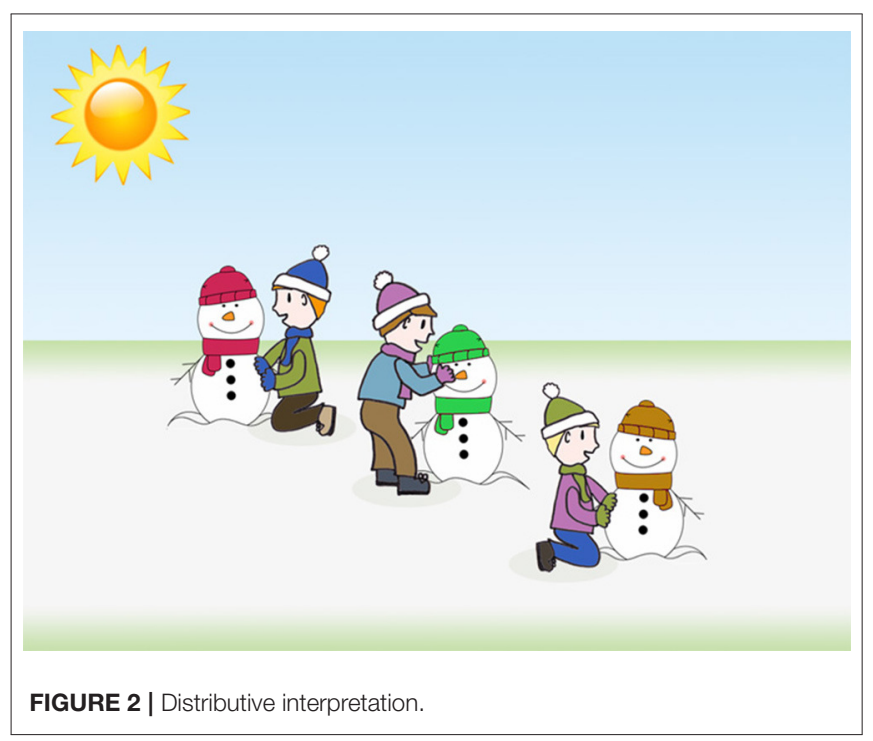

necessarily entail that $\mathrm{Al}$ is building his own snowman, Ben is building his own snowman, and Chris is building his own snowman.

Experimental studies have shown that adults disprefer distributive interpretations, unless an overt distributive marker like each is present (Gil, 1982; Brooks and Braine, 1996; Frazier et al., 1999; Kaup et al., 2002), as in (2). When each is present, adults prefer distributive interpretations almost exclusively.

(2) Each boy is building a snowman.

The preference for a collective or distributive interpretation is affected by multiple other factors as well, such as whether or not the action tends to be done with others, e.g., carrying a piano, or tends to be done individually, e.g., drinking an espresso [see also Geurts (2010); de Koster et al. (2020); Kursat and Degen (2020) for more discussion]. However, the presence or absence of distributive marking seems to be the most influential feature for lexically ambiguous predicates [see (Dotlačil and Brasoveanu, 2021) for recent results].

Studies in various languages have shown that children have different preferences than adults when interpreting plural NPs like (1). Whereas, adults prefer collective interpretations, children seem to initially prefer distributive interpretations across the board, even when no distributive marker is present (Miyamoto and Crain, 1991; Avrutin and Thornton, 1994; Brooks and Braine, 1996; Syrett and Musolino, 2013). In fact, we can identify two milestones in children's development of adult-like preferences. First, around age-seven children begin to consistently reject distributive markers like each with collective situations (Pagliarini et al., 2012; de Koster et al., 2017, 2018), suggesting that it is not until that age that children fully grasp the distributive import of distributive markers. Second, around the age of nine children begin to reject distributive interpretations if there is no distributive marking, like adults. However, they initially reject these cases at a much lower rate than adults. The rate of rejection increases steadily with age, but existing studies found that at age 11 [de Koster et al. (2018) for Dutch] and even at age 14 [Pagliarini et al. (2012) for Italian], the rates of rejection were still lower than those of adults in the same study.

In this paper, we experimentally investigate a proposal that would simultaneously explain adults' rejection of distributive interpretations with distributively unmarked sentences and, perhaps, offer an account for children's development of adult-like preferences: The implicature account of distributivity preferences developed by Dotlačil (2010). This account proposes that the preference to interpret distributively unmarked sentences as collective results from a conversational implicature. To investigate this proposal, we focus on whether or not adult preferences require working memory resources. We focus on the potential role of working memory resources in adults' distributivity preferences for two reasons. First, many studies of more established conversational implicatures have found evidence that calculating an implicature requires working memory resources. Second, in a study of children's distributivity preference development, de Koster et al. (2018) found a positive correlation between working memory capacity and adult-like preferences, suggesting that working memory plays a role in children's distributivity preferences. We thus investigate the role of working memory in distributivity preferences by limiting adults' working memory with a dual-task design. If limited working memory leads to responses more similar to children, we will have found evidence supporting an implicature account of distributivity and a role for working memory in children's non-adult preferences.

\section{IMPLICATURES AND PROCESSING}

Conversational implicatures are language-based inferences about a speaker's intended meaning that listeners make by considering alternative forms the speaker could have used (Grice, 1975). The most researched implicature is triggered by the scalar term "some." Consider (3):

(3) Teacher: "Some of my students passed the exam." 
Semantically, (3) is consistent with several students passing the exam, but also with all the students passing the exam, because some literally means "at least one." However, most listeners understand (3) to mean that not all students passed, because they will not simply interpret what the speaker literally says, but they will compare it with alternatives that the speaker could have said but did not. Because listeners expect speakers to use the most informative expression consistent with the situation, the choice by the speaker to use a weaker expression will suggest to the listener on the comparison that the stronger expression did not hold. Because all semantically entails some, all is informationally stronger than some, so an utterance with the weaker form some then implicates that the speaker believes that the stronger version with all does not hold (Horn, 1973). Because this explanation relies on the recognition of a scale of informativity (e.g., <some, all $>$, $<$ might, must $>$, <or, and $>$ ), these are also often called scalar implicatures.

Conversational implicatures are pervasive in language: Strengthened meanings are associated with specific scalar lexical items like some or most but also can be calculated on the fly. E.g., in the following short exchange, A: Did you read War and Peace? B: I read the first chapter, B's statement implicates that B did not read the rest of the book.

Dotlačil's (2010) proposal that sentences with definite plurals are interpreted collectively due to an implicature builds on the accepted view that distributively unmarked sentences, such as sentences with definite plural subjects, can semantically express both a collective and a distributive interpretation (Frazier et al., 1999). In contrast, an utterance with the distributive marker each, such as sentence (2), signals the more specific distributive interpretation and is thus informationally stronger than a distributively unmarked utterance like (1), which is ambiguous. A distributively unmarked sentence such as (1) is not specified for collective or distributive meaning, but will be interpreted as collective, because a hearer will reason that if the speaker had intended a distributive interpretation, the speaker would have used the informationally stronger form with the distributive marker each. Through the reasoning process underlying implicatures, unmarked sentences are biased to be interpreted collectively.

Note that this account proposes that the collective and the distributive interpretations have different sources: Distributive interpretations arise due to distributive marking, such as each, while collective interpretations arise because of the absence of a distributive marker due to an implicature. Because the implicature calculation requires comparing alternatives and, perhaps, others steps not necessary for a literal interpretation, it may involve greater cognitive effort. For this reason, the implicature account offers an explanation of children's non-adult interpretation preferences in terms of processing difficulties.

There are two aspects of the implicature proposal that benefit from a closer examination. First, can distributively unmarked sentences with plural definite descriptions and distributively marked sentences with each be analyzed analogously to more traditional implicatures such as some-not all? Second, what evidence is there that implicature calculation requires additional cognitive resources, in particular working memory resources?
To see if parallels exist between the well-studied implicature with some and all and the proposed implicature with plural definites and each, let us consider the sentence meanings involved in the implicature calculation in both cases. The set of situations where sentences with all, expressing an exhaustive meaning, are true is a proper subset of the set of situations where sentences with some under its literal interpretation, "some and possibly all," are true. Thus, literal some can be considered to be less informative than all: It allows the "some but not all" meaning as well as the exhaustive "all" meaning. More informative sentences with all will block the exhaustive meaning with ambiguous some so that it is preferably interpreted only as "some but not all," resulting in a pragmatically strengthened non-exhaustive meaning for sentences with some.

In a similar fashion, plural definite descriptions and distributively quantified DPs can be analyzed. Plural definite descriptions have a so-called "maximality requirement": the maximal set of the plurality modified by the definite description needs to participate in the predicated action, e.g., in (1) all members of the set of boys must build a snowman. Each as a universal quantifier also requires that all members of the restrictor set modified by the quantifier participate exhaustively in the predicated action, e.g., in (2), all members of the set of boys must also participate in snowman building. As a distributive quantifier, each imposes an additional distributive requirement, and the result is that the set of situations where sentences with the distributive quantifier each (expressing a distributive meaning) are true is a proper subset of the set of situations where sentences with the definite article the are true, and the proposition in (2) entails the less specific (1). As such, sentences with the can be considered to be less informative than sentences with each: They allow a collective as well as a distributive interpretation (e.g., Maldonado et al., 2019). The resulting scale (<plural the, each $>$ ) also fulfills an additional requirement, emphasized by van Tiel et al. (2019) and originating from Horn (1989), that members of the scale must have the same polarity in that both are positive. According to the proposed distributivity implicature, the more informative sentences with each will block the distributive meaning for the less informative sentences with the, resulting in a pragmatically strengthened collective meaning for sentences with the.

Essential to this analysis is that an implicature with plural definites would only be evoked if a speaker was aware of the unambiguous, distributive import of distributive markers and treat $<$ plural the, each $>$ as forming a scale. We expect adults to know what lexical items signal distributivity, but children have to learn this. Therefore, the proposal predicts that only children that understand the distributive meaning and the way this meaning can be marked have the prerequisite knowledge for the implicature. Children are generally considered to understand the meaning of distributive markers if they consistently reject them with collective situations, which has been found experimentally to be around age seven (Pagliarini et al., 2012; de Koster et al., 2017, 2018). Only after this age will they be able to infer that the absence of distributive marking conversationally implicates collectivity. This prediction has been previously experimentally investigated by Pagliarini et al. (2012) in Italian, 
de Koster et al. (2017) in Dutch, and Padilla-Reyes (2018) in Spanish. All three studies found a correlation between children's rejection of collective situations with distributive marking and children's rejection of distributive situations when distributive marking is not present, consistent with the predictions of the implicature account.

Why would implicature calculation be effortful? And what experimental evidence supports this claim? Implicature accounts differ as to whether they see it as a primarily pragmatic (e.g., Gricean) process, where implicature is the product of the listener's expectation that speakers will be as informative as possible, or as a semantic process (Chierchia, 2004, 2006), where strengthened meaning is argued to originate from an unpronounced operator, $\mathrm{O}$, that signals that stronger alternatives do not apply [i.e., "[O]nly" the literal meaning is intended]. Despite these different assumptions, both pragmatic and semantic accounts of implicature identify at least two steps in implicature calculation that could be potentially cognitively demanding: The decision whether or not to calculate an implicature and the derivation and comparison of alternatives, both considered to be pragmatically driven processes (see, Geurts, 2010; e.g., Chemla and Singh, 2014).

Multiple studies have, in fact, found evidence that verifications of sentences with some-not all implicatures take more time than the lower-bounded, literal interpretation of some. This has been shown with timed sentence verification (Bott and Noveck, 2004), self-paced reading (Breheny et al., 2006; Chemla and Bott, 2013), eye-tracking (e.g., Huang and Snedeker, 2009), mouse tracking (Tomlinson et al., 2011), and looking at response times, with speed accuracy trade-off (SAT) methods (e.g., Bott et al., 2012). Most relevant for our research, however, are the experiments that focused on determining if there is a memory cost involved in the calculation of scalar implicature, using dual-task designs. These experiments ask the participants to judge sentences while their working memory is loaded (De Neys and Schaeken, 2007; Dieussaert et al., 2011; Marty and Chemla, 2013; Marty et al., 2013; van Tiel et al., 2019; Ryzhova and Demberg, 2020). Most of these studies had participants memorize dot patterns on a $3 \times 3$ matrix, which they then had to recreate after judging sentences that could invoke an implicature. Most studies compared linguistic performance on low-working memory load patterns, with a systematic threedot pattern (all horizontal or all vertical), to performance with high-load patterns, which had four dots. De Neys and Schaeken (2007) found that participants under a high-working memory load made significantly fewer some-not all implicatures (around 10\% less) compared to a low-working memory load. Dieussaert et al. (2011) used an identical design but investigated the role of individual working memory capacity by also measuring participants' working memory spans in a separate task. They found fewer implicature calculations under a high load but only for participants with low-working memory capacity. Marty and Chemla (2013) also used a similar design and found that loading working memory decreased the rate of implicatures but had no effect on semantically equivalent only some sentences where the negation of the alternative is made explicit, a result that is unexpected under a semantic account of implicature ${ }^{1}$.

The type of implicature may also influence whether or not working memory resources are involved. Marty et al. (2013) used a dual-task design with a backward letter sequence reproduction task. They found a decrease in implicature interpretations with some-not all implicatures under a high memory load but found no effect with number items, which should implicate an exact interpretation (e.g., three means three and no more) ${ }^{2}$. In a recent study, van Tiel et al. (2019) used a dual-task design to investigate several scalar words, using a between-subjects design to compare participants under no load, a low working memory load, and a high working memory load. They found that the influence of loading working memory varied by implicature type: Some implicatures, such as some-not all, showed a lower rate of calculation already in the low-load condition compared to the no-load condition, whereas others only showed an effect between the low-load and the high-load conditions. Ryzhova and Demberg (2020) also carried out a dual-task study, using dot-tracking as the secondary task. Participants made fewer particularized conversational implicatures under a high memory load compared to a low-memory load. In summary, the existing dual-task studies have all found that loading working memory with a dual task lowers the rate of implicature calculation.

In contrast to the dual-task studies, which focused on working memory resources, a number of other studies, which are primarily eye-tracking studies, have failed to find evidence that implicature calculation requires additional cognitive resources. In a visual-world study, Grodner et al. (2010) failed to find that some-not all implicature calculations required greater processing times when they modified the materials from (Huang and Snedeker, 2011). Politzer-Ahles and Fiorentino (2013), Hartshorne and Snedeker (2014), in an eye-tracking reading experiment, and Politzer-Ahles and Husband (2018), all also failed to find evidence of additional processing costs for implicatures. For implicatures based on the <not all, none $>$ scale, Cremers and Chemla (2014) (Exp. 1) and Romoli and Schwarz (2015) both found that participants were faster at implicature calculation than the literal interpretation. In a visual world eye-tracking study, Degen and Tanenhaus (2016) found no difference between pragmatic and literal interpretations of some. Kursat and Degen (2020), investigating reaction times with some-not all implicatures found evidence for two populations: pragmatic responders who tended to always calculate implicatures and who were faster at these interpretations than at lower-bounded interpretations, and literal responders. Like the results from Dieussaert et al. (2011), this

\footnotetext{
${ }^{1}$ Because only some is semantically equivalent with the some-not all implicature it offers a useful control condition to determine whether the implicature itself requires working memory resources rather than, e.g., verification. Unfortunately, for definite descriptions there is not an obvious semantic equivalent that could be used as a control expression. Future research will have to investigate this question with other methods.

${ }^{2}$ Note however that it is currently a matter of debate whether or not numerals should be expected to give rise to implicatures. See Marty and Chemla (2013) for a discussion.
} 
shows that there may be individual differences in implicature calculation tendencies.

Another issue in experimental implicature research is that many studies focus on participants' end-state judgments without further information about the interpretation process. Because end-state judgments are a culmination of multiple interpretation processes, both semantic and pragmatic, ${ }^{3}$ it can be hard to determine what influences the participants' final judgment.

If implicatures do require additional resources, exactly what resources and at what step in their interpretation these become relevant is still a topic of investigation. Dotlačil's (2010) implicature account of distributivity preferences claims to both explain adults' preferences and offer an account for children's non-adult preferences by attributing them to children's difficulties in calculating implicatures. Dotlačil does not make specific claims about what aspect of distributivity interpretation preferences might require processing resources. But because many experimental studies did find a role for working memory in implicature calculation, and because de Koster et al. (2018) found that children's tendency to reject distributive situations without distributive marking was found to be positively correlated with these children's working memory capacity, we decided to investigate the role of working memory in distributivity preference in adults.

If we find that limiting working memory capacity in adults decreases their rates of acceptance of distributive readings with distributively unmarked sentences, then children's tendency to allow distributive readings with distributively unmarked sentences might be explained as a consequence of their lower working memory capacity. This result would then be consistent with the predictions of Dotlačil's implicature account of distributive preferences. If we fail to find an effect of limiting working memory capacity, then this would not rule out an implicature calculation if there is no processing cost for implicature (as some research has found). However, this would make the explanation less attractive in that it would fail to offer a processing explanation for children's non-adult interpretation preferences.

We designed our experiment along the lines of previous dualtask experiments, investigating the influence of working memory on implicature calculation. To our knowledge, we are the first to study distributivity interpretations while limiting working memory capacity. Our study thus provides novel empirical evidence, illuminating the role of memory in the interpretation of plural definites.

For practical reasons, we carried out our experiment in Dutch. English has two distributive quantifiers: each and every. Each and every are both universal quantifiers that are compatible with distributivity. Whereas every only requires partial distributivity, each requires full distributivity (Tunstall, 1998), in that a distributive sentence like (2) must entail that for each individual member of the set of boys, it must hold that he was building a snowman. Dutch also has two distributive quantifiers, elke and iedere. However, experimentally, these quantifiers have been shown to have the exact same interpretation with respect to

${ }^{3}$ We thank an anonymous reviewer for stressing this point. distributivity preferences (van der Ziel, 2012; Spenader and Bosnic, 2018), so we will simply use elke. Research also suggests that both are more similar to every than each, being partially distributive (Tunstall, 1998) and thus compatible with collective situations in some cases (Rouweler and Hollebrandse, 2015; de Koster et al., 2017). For this reason, we expect that we will see greater acceptance rates of elke with collective situations than has been found for each, which is fully distributive.

\section{METHOD}

\section{Participants}

Fifty-eight students from the University of Groningen were paid to participate. They were divided into two groups: a WM Load group (42 participants; 13 men; mean age, 21.9; age range, 1827) and, to establish a baseline for performance, a No WM load group (16 participants: six men; mean age, 23.9; age range, 2028). All participants were native speakers of Dutch. This study was carried out in accordance with the recommendations of the Research Ethics Committee (CETO) of the Faculty of Arts of the University of Groningen, and they approved the protocol. We also obtained written informed consent from all the participants prior to testing.

\section{Design}

The WM Load group carried out a dual-task experiment, consisting of two tasks, a linguistic task and a memory load task: while participants interpreted a sentence (the linguistic task), we manipulated their WM load by asking them to memorize a sequence of digits (the digit-span task). For this group, the experiment had a $2 \times 2 \times 2$ design with the factors PICTURE [collective (Figure 1) vs. distributive (Figure 2)], SENTENCE (de "the" vs. elke "each") and WM LOAD (low vs. high).

The No WM load group received the linguistic task without the digit span task. This group was not tested in a WM Load condition and, therefore, received the experiment in a $2 \times 2$ design, with the factors PICTURE and SENTENCE but without the factor WM LOAD. The remaining procedure was the same for the two groups.

\section{Linguistic Task}

The linguistic task was a sentence-picture verification task. Participants saw a picture on the computer screen and had to judge whether it matched a recorded sentence by pressing a key on the keyboard.

\section{Digit-Span Task}

At the start of each trial, participants had to memorize a sequence of three or six digits (low and high WM load conditions, respectively), presented on screen for $1 \mathrm{~s}$ each. Digits were randomly chosen from 1 to 9 , and consecutive digits always differed. After each linguistic item, participants had to recall the digits by typing them in the same order as they appeared.

\section{Materials}

The materials consisted of four practice items, 64 test items, 48 implicature control items and 16 task control items (eight true and eight false items), resulting in a total of 132 items. 
The experiment was divided into two blocks (preceded by four practice trials), with 64 items per block. The low (three digits) and high (six digits) WM load conditions were presented in different blocks. Block order (either low or high WM load in the first block) was a between-subject factor. The Latin-square design of the test items, together with the factor block order, resulted in eight lists. Item order was randomized for each participant, and the participants were randomly assigned to a list.

\section{Test Items}

The 64-test items tested the factors PICTURE [collective (Figure 1) vs. distributive (Figure 2)] and SENTENCE [de "the" (4) vs. elke "each" (5)].

(4) De jongens bouwen een sneeuwpop. The boys are building a snowman.

(5) Elke jongen bouwt een sneeuwpop. Each boy is building a snowman.

Eight different transitive verbs were used: build, wash, push, pull, carry, lift, hold or paint (in Dutch: bouwen, wassen, trekken, duwen, dragen, tillen, vasthouden, verven), and the grammatical subjects and objects of these verbs varied across the items. The design resulted in four conditions: The-Collective, TheDistributive, Each-Collective, and Each-Distributive. The items of condition The-Distributive test proposed implicature. Each participant saw 16 items in each of the four conditions, resulting in 64 test items ( 32 items per block).

\section{Implicature Control Items}

In addition to the test items, participants also received 48 implicature control items to mask the goal of the experiment and to be able to compare the results of the test items to the results of the well-investigated some-not all implicature in a dual-task setting.

(6) Sommige jongens vissen.

Some boys are fishing.

(7) Enkele meisjes dansen.

Some girls are dancing.

The implicature control items consisted of two sentence types with the scalar expressions sommige "some" ${ }_{1}$ "(6) or enkele "some 2 " (7) (24 items per sentence type). In contrast to enkele, which merely expresses existential quantification ("there are some..."), sommige additionally indicates that the individuals introduced by the quantifier have something in common that distinguishes them from other individuals (de Hoop and Kas, 1989; Banga et al., 2009). For each item, a different intransitive verb was used (e.g., fishing, dancing, singing, and sleeping).

Both sentence types were combined with four picture types where either zero, one, two or three (i.e., all) of the three actors are performing the action denoted by the sentence. This resulted in eight implicature control combinations. The participants received six items per combination (three items per block). The implicature control items were not constructed via a Latin-square design: All the participants received the same sentence-picture combinations as implicature control items. The examples of the implicature control items are presented in the Supplementary Material.
The implicature control items with a picture with three actors serve as a control to test whether the participants generate a some-not all implicature and whether or not this implicature generation is affected by the dual-task setting.

\section{Task Control Items}

The participants also received 16 task control items. These control items were straightforwardly true or false items and were used to check the participants' attention as well as general task effects such as a possible "yes"-bias. Examples of a true (8) and a false (9) task control item are presented below. The corresponding pictures for items (8) and (9) can be found in the Supplementary Material. The experiment contained eight true task control items and eight false task control items. If the participants answered more than $25 \%$ of the task control items incorrectly, they were excluded from the analysis.

(8) De jongen drinkt een pakje melk.

The boy is drinking a carton of milk.

(9) Het meisje drinkt een glas limonade.

The girl is drinking a glass of lemonade.

\section{Procedure}

The participants performed the experiment in a quiet room at the University of Groningen. Participants were shown the pictures on the computer screen while the sentences were played via a speaker. The experimenter was present during the entire experiment.

The experiment started with instructions and four practice trials. For each trial, the participants first saw a digit sequence on screen, followed by a picture and a recorded sentence. The recorded sentence was played only once. They then had to judge sentence acceptability by pressing a green (accept) or red (reject) key. Finally, they had to type in the memorized digits. Participants had $10 \mathrm{~s}$ to judge the sentences, with a visual warning message after $7 \mathrm{~s}$. Next, they had $5 \mathrm{~s}$ to recall the digits in the low WM load condition and $10 \mathrm{~s}$ in the high WM load condition. Pilot testing had shown that this provided the participants with sufficient time.

Each trial ended with feedback to participants on how many digits were recalled correctly. A waiting penalty ensured that participants focused on the WM task and prevented rushing: One incorrect digit resulted in a 1-s waiting penalty, two incorrect digits in a 2-s waiting penalty, etcetera. Selfpaced breaks were provided after every 16 items, and the participants had a forced break of at least $2 \mathrm{~min}$ in between the two blocks.

The procedure for the two participant groups was similar, including breaks, with the exception that the No WM load group only received the linguistic task. Per trial, the following measures were collected: Accuracy of reproducing the digits in the digitspan task, and yes/no responses and response times for the test items, implicature control items, and task control items in the linguistic task.

\section{Predictions}

The linguistic task tests four conditions: The-Distributive, EachCollective, The-Collective, and Each-Distributive. 
Condition The-Distributive tests whether working memory limitations play a role in children's non-adult acceptance of distributive readings with unmarked sentences. This condition, therefore, also tests the implicature account of distributivity preferences. A "yes" response (acceptance) in this condition would be consistent with a literal interpretation of the distributively unmarked sentence, and a "no" response (rejection) would be consistent with the derivation of an implicature. If there is an effect, we also expect the participants in the No WM load condition and the participants under a low WM load to show a higher rate of rejection than the participants under a high WM load. This result would then be parallel to previous findings for the "some-not all" implicature (De Neys and Schaeken, 2007; Dieussaert et al., 2011; Marty and Chemla, 2013; Marty et al., 2013). This result would also be consistent with the child language data, showing that rejection of the The-Distributive condition in children correlates with working memory capacity (de Koster et al., 2018). Importantly, this is the only condition we expect to be affected by WM load. In addition, we also expect to see higher response times for pragmatic responses compared to literal responses, following the findings of Bott and Noveck (2004).

We do not expect condition Each-Collective to be affected by WM load, and we expect the items of this condition to be rejected due to the distributive character of each. Experimental results show that from around age 7;0, children are adultlike in their responses to distributively marked sentences with collective situations. Earlier non-adult acceptance is attributed to children being unaware of the distributive nature of each. However, it should be noted that the Dutch elke (tested in the current study), contrary to its English counterpart each, is only partially distributive and has been found to be more acceptable in collective situations (Rouweler and Hollebrandse, 2015; de Koster et al., 2017). Acceptances of items in this condition are, therefore, not unexpected but are predicted to be independent of WM load.

Condition The-Collective is predicted to be unaffected by WM load too. Sentences with the are semantically ambiguous between a collective and a distributive interpretation, so the collective interpretation is a semantically appropriate interpretation for sentences with plural definite subjects. This prediction is supported by child language data, showing that children fully accept the sentences with a collective interpretation from age 4 and onward (Italian: Pagliarini et al., 2012; Dutch: de Koster et al., 2017; Spanish: Padilla-Reyes, 2018). The implicature account of distributivity preferences does not predict that a WM load would have an effect on this condition either.

Finally, condition Each-Distributive is also predicted to be unaffected by a WM load. The items in this condition are predicted to be fully accepted since the distributive quantifier each is fully compatible with the distributive interpretation. Child language data show children from age 4 until age 14 fully accept distributive interpretations for sentences with each (Pagliarini et al., 2012; de Koster et al., 2017; Padilla-Reyes, 2018), which is expected because each is semantically distributive.

The implicature control items, testing the "some-not all" implicature, can be used to make a comparison with the results of previous studies testing this implicature
(De Neys and Schaeken, 2007; Dieussaert et al., 2011; Marty and Chemla, 2013; Marty et al., 2013). The items of our implicature control "Some-All" condition consist of sentences with sommige "some" in combination with a picture in which all the actors are performing the action denoted by the predicate. A "yes" response in this condition indicates a literal interpretation, in which the "at least one and possible all" meaning of "some" is accepted. A "no" response, on the other hand, indicates a pragmatic interpretation in which some is interpreted as "some but not all." We expect to see fewer pragmatic "no" responses under a high WM load, similar to the findings of previous studies (De Neys and Schaeken, 2007; Dieussaert et al., 2011; Marty and Chemla, 2013; Marty et al., 2013). Following the findings of Bott and Noveck (2004) and others, we also expect to observe longer response times for these responses because calculating an implicature comes at a cost.

\section{RESULTS}

Two participants of the WM Load group were excluded from the analysis: One participant did not complete the experiment due to technical problems, and one participant gave incorrect answers to more than $25 \%$ of the task control items. All remaining participants were included in the analysis.

\section{Digit-Span Task}

The WM Load group participants remembered $94 \%$ of the digits correctly in the low WM load condition (three digits) and 75\% of the digits in the high WM load condition (six digits). This drop in performance is significant [paired- $\mathrm{t}_{(39)}=13.873$; $p<0.001$ ], indicating that the high WM load condition was, indeed, more difficult. Furthermore, the linguistic condition had no effect on the percentage of correctly recalled digits. This shows that the participants focused on digit recall performance throughout the experiment, irrespective of linguistic condition.

\section{Linguistic Task}

\section{Responses to Test Items}

Figure 3 shows the mean acceptance rates for all four linguistic conditions per WM load. The collected data were analyzed, using generalized mixed effect logistic modeling [function glmer(): lme4 package in $\mathrm{R}$, version 3.6.3].

The models were constructed via an iterative forward fitting procedure with model comparisons (cf. Baayen et al., 2008; Wieling et al., 2011; Ko et al., 2014) based on the evaluation of Akaike's information criterion (AIC) (cf. Burnham and Anderson, 2002; Akaike, 2011; Ko et al., 2014; Wieling et al., 2014). An AIC decrease of more than two indicates that the goodness of a fit of the model improves significantly (Akaike, 2011). The AIC values were obtained via model comparisons, using ANOVA testing [function anova() in R]. We determined whether the following fixed-effect factors improved the goodness of fit of the model: SENTENCE (each, the), PICTURE (collective, distributive), BLOCK (first, second), WM LOAD (no load, low, high), and VERB. The dependent variable was the response (0 for rejection, 1 for acceptance). The final model (Table 1) included the fixed factors SENTENCE, PICTURE, WM LOAD, and BLOCK. 


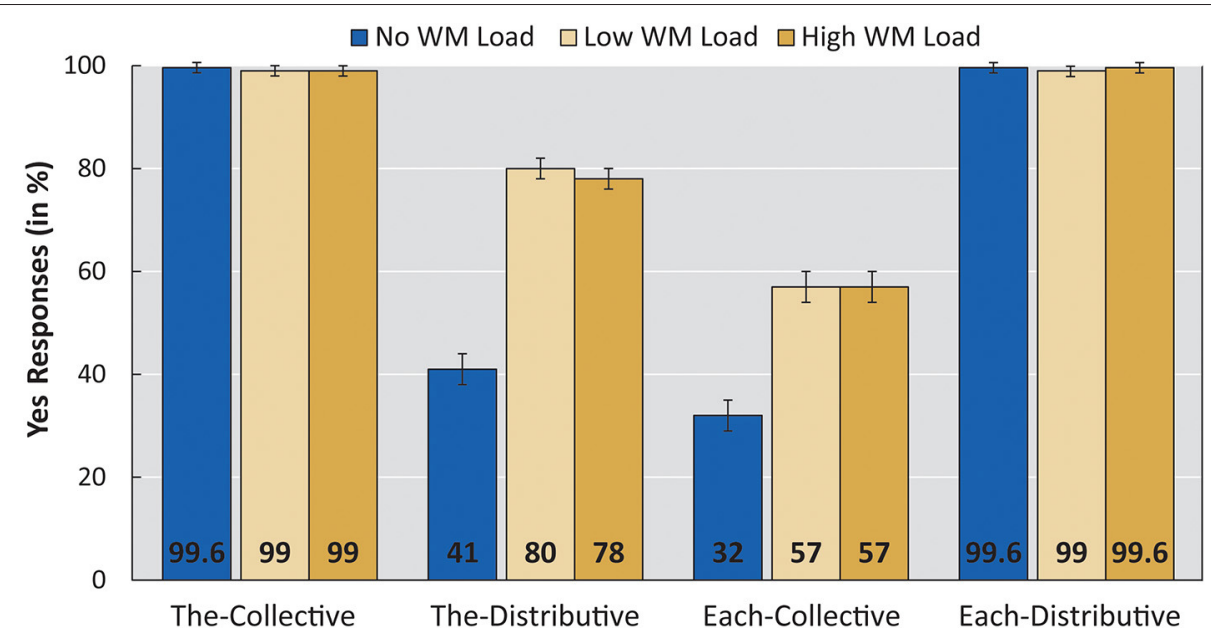

FIGURE 3 | Mean acceptance rates per linguistic condition per WM load (No load, Low, High). Error bars show standard error. The WM Load group was tested with Low and High WM load; the No WM load group was tested on the linguistic task only. Sentences contained either de "the" or elke "each" and pictures showed either a collective action or a distributive action.

TABLE 1 | Overview of the final model for the responses to the test items, with reference levels: Sentence: "De" "The," Picture: Distributive, WM Load: No Load, and Block: 1.

\begin{tabular}{lrrrr}
\hline Predictors & Estimate $(\boldsymbol{\beta})$ & SE & $\boldsymbol{z}$ & $\boldsymbol{p}$ \\
\hline Intercept & 0.3307 & 0.844 & 0.695 & $<0.001$ \\
Sentence "Elke" "Each" & 13.316 & 2.528 & 5.267 & $<0.001$ \\
Picture collective & 9.470 & 2.193 & $4.319<0.001$ \\
WM load low & 2.809 & 1.049 & $2.679<0.01$ \\
WM load high & 2.730 & 1.048 & 2.605 & $<0.01$ \\
Block 2 & -0.419 & 0.356 & -1.180 & 0.238 \\
Sentence "Elke" $\times$ Picture Collective & -24.392 & 3.584 & -6.807 & $<0.001$
\end{tabular}

The factor VERB did not significantly improve the model fit and was left out. The maximal random-effects structure licensed by the data included a random intercept for participants, items and by-participant random slopes for SENTENCE, PICTURE, and BLOCK.

A main effect of SENTENCE and PICTURE was found, as well as an interaction between the two. Crucial to our findings is the significant difference between the No WM load group and each of the low and high WM load conditions of the WM Load group (low: $\beta=2.809 ; \mathrm{z}=2.679 ; p=0.007$, high: $\beta=2.730$; $\mathrm{z}=2.605 ; p=0.009$ ). In line with our predictions, participants accepted significantly more items of condition The-Distributive in the WM load group compared with the No WM load group.

A releveled model revealed no significant difference between the low and high WM load conditions within the WM load group $(\beta=-0.079 ; z=-0.235 ; p=0.814)$. The low and high WM load conditions had acceptance rates of condition The-Distributive to the same degree.

To check for an influence of the factor BLOCK-ORDER (low or high WM load in the first block), we performed a separate analysis on the data of the WM load group, with a similar model.
In this model, BLOCK-ORDER did not improve the model fit. This shows that participants' acceptance of The-Distributive items was not influenced by whether they received the low or high WM load condition first. Note that it is not possible to add the factor BLOCK-ORDER to the final model presented in Table $\mathbf{1}$ (analyzing the WM load and the No WM load group together) for reasons of collinearity.

\section{Responses to Implicature Control Items}

We also analyzed the responses of the implicature control items

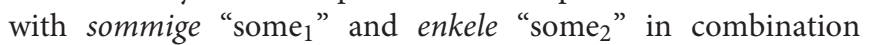
with pictures where three (i.e., all) actors are performing the action denoted by the sentence, to check how our WM manipulation affected the "some-not all" implicature. These items are compared to implicature control items with pictures where two actors are performing the action denoted by the sentence, since these latter items do not give rise to an implicature and should be considered true. Figure 4 presents the results for these items. The remaining implicature control combinations (with pictures with zero actors or one actor) were omitted from the figure and further analysis, since they are expected to be judged as false, because sentences with Dutch sommige "some." and enkele "some 2 " require reference to at least two individuals (Broekhuis and den Dikken, 2012, p. 895).

Models were again constructed via an iterative forward fitting procedure. Using model comparisons (cf. Baayen et al., 2008) based on the AIC values, we determined which fixed-effect factors would improve the model fit. The final model (Table 2) included the fixed factors SENTENCE, PICTURE, and WM LOAD. The dependent variable was the response ( 0 for rejection, 1 for acceptance). The maximal random-effects structure licensed by the data included a random intercept for participants and by-participant random slopes for SENTENCE and PICTURE.

A main effect of SENTENCE and PICTURE was found, but an interaction between the two did not improve the model fit. 


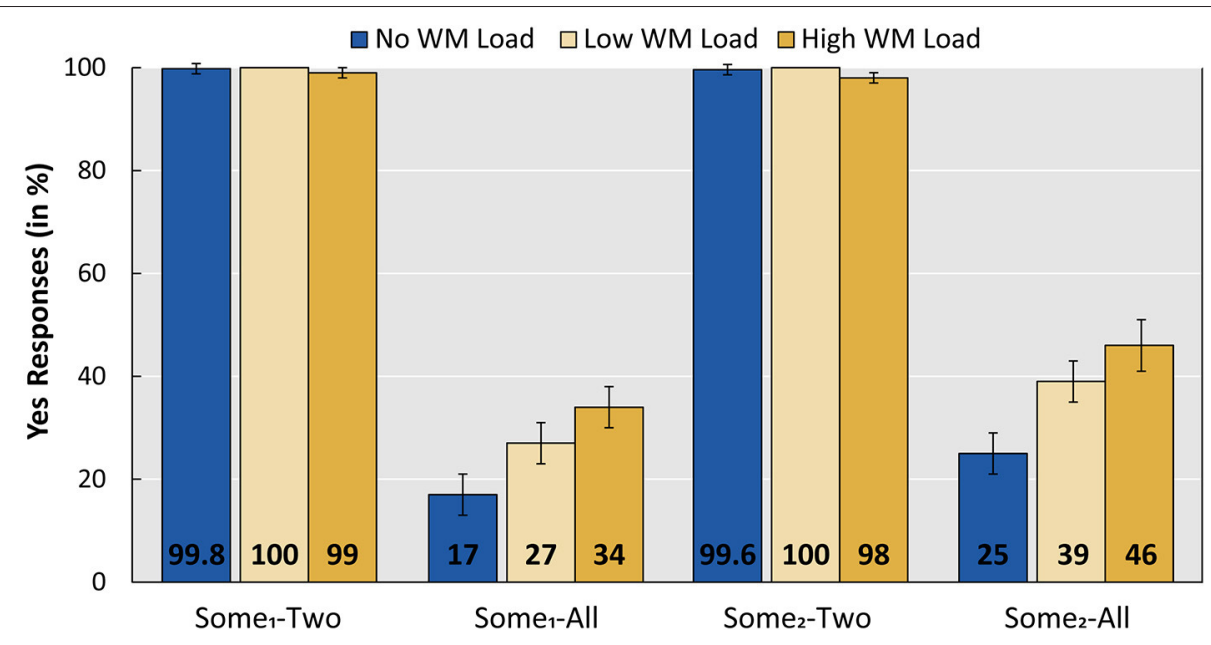

FIGURE 4 | Mean acceptance rates per implicature control condition per WM load (No load, Low, High). Error bars show standard error. The WM Load group was tested with Low and High WM load; the No WM load group was tested on the linguistic task only. Sentences contained either sommige "some1" or enkele "some2," and pictures showed either two out of three actors or all three actors performing the action denoted by the sentence.

TABLE 2 | Overview of the final model for the responses to the implicature control items, with reference levels: Sentence: "Sommige" "Some 1 ," Picture: All, WM Load: high.

\begin{tabular}{lcccc}
\hline Predictors & Estimate $(\boldsymbol{\beta})$ & SE & $\boldsymbol{z}$ & $\boldsymbol{p}$ \\
\hline Intercept & -1.849 & 0.755 & -2.447 & $<0.05$ \\
Sentence "Enkele" "Some, & 1.448 & 0.456 & 3.177 & $<0.01$ \\
Picture two & 9.163 & 1.636 & 5.601 & $<0.001$ \\
WM load no load & -2.188 & 1.089 & -2.009 & $<0.05$ \\
WM load low & -0.653 & 0.311 & -2.099 & $<0.05$ \\
\hline
\end{tabular}

Crucial, however, is the significant difference between the high WM load condition (six digits) and both the low WM load condition (three digits) and the No WM load group (low: $\beta=$ $-0.653 ; \mathrm{z}=-2.099 ; p=0.0358$, no load: $\beta=-2.188 ; \mathrm{z}=-2.009$; $p=0.0445)$. In line with the predictions regarding the "some-not all" implicature, participants accepted significantly more items of condition Some S $_{1}$ All (accepting the literal interpretation of "some") under a high WM load. A releveled model with "some 2 " enkele as the reference level revealed that a similar pattern holds for condition Some 2 -All.

An additional releveled model (with the low WM load as a reference level) revealed no significant difference between the low WM load condition and the No WM load group $(\beta=1.535 ; \mathrm{z}=$ $1.421 ; p=0.155)$. This means that the participants' calculation of "some-not all" implicatures was only affected by the high WM load condition of six digits.

\section{Responses to Task Control Items}

The task control items (straightforwardly true or false items) were included to check for participants' attention to the linguistic task. Overall, participants answered 95\% of all task control items correctly, which shows that they paid sufficient attention to the linguistic task.
To investigate whether the difference we found in acceptance rates between the WM load group and the No WM load group for the test items could be attributed to a general tendency to more readily accept items when WM is loaded, we also analyzed participants' performance on the false task control items (that required a "no" response).

The WM load group participants answered $89 \%$ of the false control items correctly in the low WM load condition (three digits) and $88 \%$ of the false control items in the high WM load condition (six digits). This difference was not significant [paired- $_{(39)}=0.443 ; p=0.660$ ].

Participants of the No WM load group answered $92 \%$ of the false control items correctly. This did not differ from the false control item performance of the WM load group [unpaired- $\mathrm{t}_{(36)}$ $=-1.516 ; p=0.138$.

The results from the false task control items indicate that participants were not simply more accepting of experimental items because of the cognitive burden of the secondary task, but, instead, the difference in acceptance rates between the WM load group and the No WM load group must have a different explanation such as e.g., the costs associated with calculating the interpretation.

\section{Response Times of Test Items}

To test the assumption that implicature calculations require more time (in addition to memory resources), we also analyzed response times (RTs). Figure 5 presents boxplots of RTs for all four linguistic conditions for "yes" and "no" responses separately and per WM load. RTs were measured from the onset of picture and sentence presentation until button press. Outliers were excluded following the interquartile range rule, excluding data points that are more than one and a half times the interquartile range below the first and above the fourth quartile $(5.4 \%$ of the data was removed). 


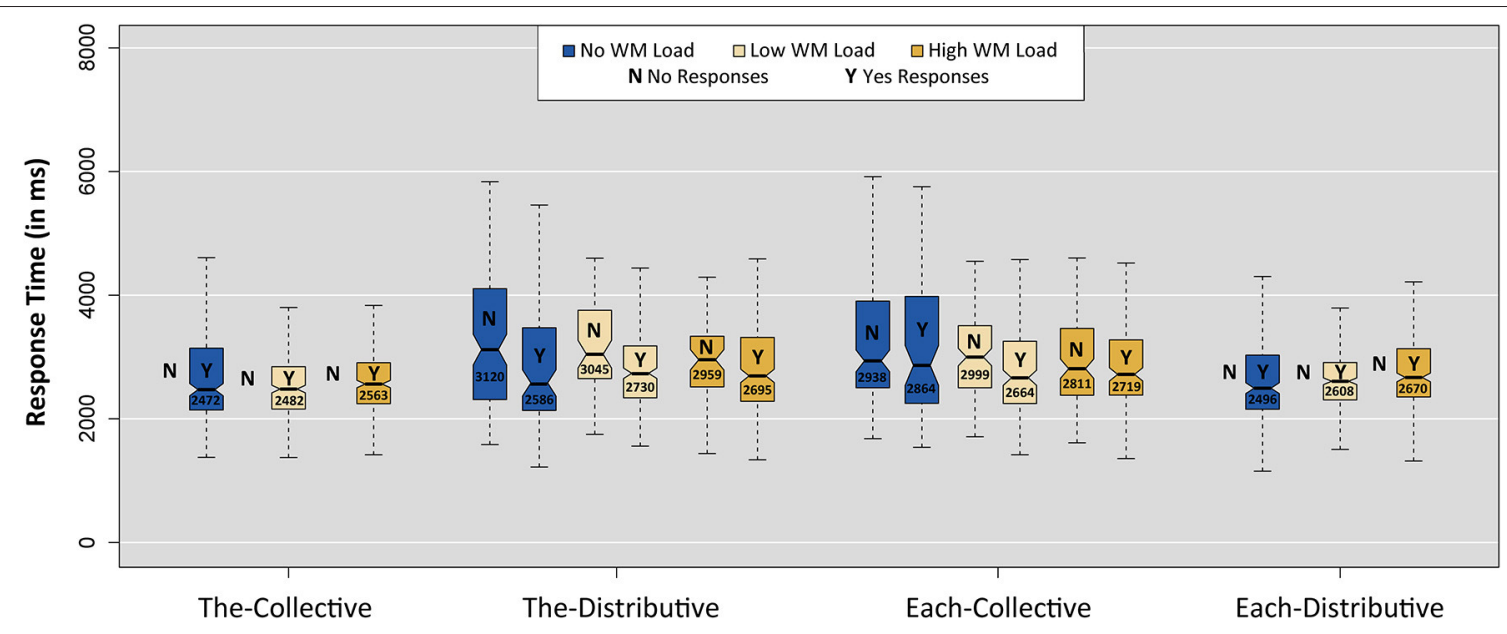

FIGURE 5 | Boxplots of response times per condition and WM load for both "yes" and "no" responses. Notches indicate 95\% confidence intervals (Chambers et al., 1983). Note that conditions The-Collective and Each-Distributive had too few "no" responses to be plotted (only seven "no" responses in total).

We performed three different analyses. We first wanted to find out whether it was, indeed, the case that the pragmatic interpretation of the proposed implicature (a "no" response in condition The-Distributive) takes more time than the literal interpretation (a "yes" response in condition The-Distributive). This difference was previously observed by Bott and Noveck (2004) for the "some-not all" implicature.

Second, we wanted to examine whether or not the response times of the pragmatic interpretation were influenced by a WM load. In their dual-task study, De Neys and Schaeken (2007) found that pragmatic interpretations under a high WM load took significantly longer than pragmatic interpretations in the control condition involving only a low WM load.

We also looked more closely into the response pattern of condition Each-Collective. The responses indicated that loading adults' WM not only increased their acceptance of TheDistributive items but also their acceptance of Each-Collective items (see Figure 3). This is unexpected, since we do not predict an implicature in this condition. The verification of this condition is expected to be based on the semantics of Dutch elke and should, therefore, not be influenced by a limited WM capacity. Analyzing the response times of condition Each-Collective can show if a similar process underlies the interpretations of the items in conditions The-Distributive and Each-Collective.

We did not analyze the response times of the implicature control items because there were too few items for a proper analysis.

\section{Pragmatic vs. Literal Interpretations}

To find out whether or not the proposed pragmatic interpretations, indeed, took more time than the proposed literal interpretations, we analyzed the log-transformed RTs of condition The-Distributive, using linear mixed effect modeling [function lmer(): lme 4 package in $\mathrm{R}$, version 3.6.3]. We included the factor RESPONSE, separating the RTs of the "no' responses from the "yes" responses, since a "no" response indicates a
TABLE 3 | Overview of the model comparing the response times of the pragmatic and literal interpretations, with reference levels: Response: "No," and Block: 1.

\begin{tabular}{lrcccc}
\hline Predictors & Estimate $(\boldsymbol{\beta})$ & SE & df & $\boldsymbol{t}$ & $\boldsymbol{p}$ \\
\hline Intercept & 8.127 & 0.040 & 47 & 200.159 & $<0.001$ \\
Response "Yes" & -0.168 & 0.039 & 36 & -4.288 & $<0.001$ \\
Block 2 & -0.165 & 0.033 & 92 & -4.988 & $<0.001$ \\
Response "Yes" × Block 2 & 0.124 & 0.036 & 99 & 3.395 & $<0.001$ \\
\hline
\end{tabular}

pragmatic interpretation and a "yes" response indicates a literal interpretation.

Based on model comparisons, using the Akaike Information Criterion, the final model (Table 3) included the fixed factors RESPONSE and BLOCK. We also included random intercepts for participants, items, and by-participant random slopes for RESPONSE and BLOCK. The dependent variable was the response time in milliseconds (log-transformed).

A main effect of RESPONSE and BLOCK was found, as well as an interaction between the two. Crucially, the main effect of RESPONSE $(\beta=-0.168 ; t=-4.288 ; p<0.001)$ indicates that "no" responses in condition The-Distributive were significantly slower than "yes" responses, following the prediction that pragmatic interpretations take more time than literal interpretations.

The significant effect of the factor BLOCK $(\beta=-0.165 ; t=$ $-4.988 ; p<0.001)$ indicates that participants were generally faster in block 2 compared to block 1 . The significant interaction between RESPONSE and BLOCK $(\beta=0.124 ; t=3.395 ; p<0.001)$ indicates that the difference between the responses ("yes" and "no") is smaller in block 2 compared to block 1 . These findings could be explained as an effect of task experience. Similar block effects have been found in other dual-task studies (e.g., van Rij et al., 2013).

To be sure that the difference in RTs between the pragmatic and literal interpretation was not caused by the possibility that 
TABLE 4 | Overview of the model comparing the response times of the "no" responses in conditions The-Distributive and Each-Collective, with reference levels: Condition: "The-Distributive," and Block: 1.

\begin{tabular}{lccccc}
\hline Predictors & Estimate $(\boldsymbol{\beta})$ & SE & df & $\boldsymbol{t}$ & $\boldsymbol{p}$ \\
\hline Intercept & 8.159 & 0.035 & 49 & 234.035 & $<0.001$ \\
Condition Each-Collective & -0.061 & 0.027 & 28 & -2.279 & $<0.01$ \\
Block 2 & -0.140 & 0.018 & 55 & -7.926 & $<0.001$ \\
\hline
\end{tabular}

TABLE 5 | Overview of the model examining the influence of WM load on the pragmatic interpretation, with reference levels: WM Load: "No Load," and Block: 1.

\begin{tabular}{lccccr}
\hline Predictors & Estimate $(\boldsymbol{\beta})$ & SE & df & $\boldsymbol{t}$ & $\boldsymbol{p}$ \\
\hline Intercept & 8.219 & 0.059 & 32 & 139.32 & $<0.001$ \\
WM load low & -0.086 & 0.077 & 38 & -1.120 & 0.270 \\
WM load high & -0.099 & 0.077 & 38 & -1.283 & 0.207 \\
Block 2 & -0.155 & 0.031 & 224 & -4.946 & $<0.001$
\end{tabular}

it would take longer in general to provide a "no" response than a "yes" response, regardless of the tested condition, we also compared RTs on "no" responses in the The-Distributive condition (requiring the hypothesized implicature) to RTs on "no" responses in the Each-Collective condition (not requiring an implicature).

Based on model comparisons, using the Akaike Information Criterion, the final model (Table 4) included the fixed factors CONDITION and BLOCK. We also included random intercepts for participants, items, and by-participant random slopes for CONDITION. The dependent variable was the response time in milliseconds (log-transformed).

We found a main effect of CONDITION $(\beta=-0.061 ; t$ $=-2.279 ; p<0.01)$, as well as $\operatorname{BLOCK}(\beta=-0.140 ; t=$ -7.926; $p<0.001)$. The main effect of BLOCK shows that participants' "no" responses were faster in block 2 than in block 1 , similar to the previously found BLOCK effect. The main effect of CONDITION shows that "no" responses in the EachCollective condition were significantly faster than "no" responses in the The-Distributive condition. This finding indicates that the difference in RTs between the pragmatic interpretation ("no" response) and the literal interpretation ("yes" response) in condition The-Distributive was not caused by a general difference in RTs between "yes" and "no" responses.

\section{Implicature Interpretations Under WM Load}

We also examined the influence of a WM load on the response time for rejections of the The-Distributive condition. We, therefore, analyzed the log-transformed RTs of the pragmatic interpretations ("no" responses) of condition The-Distributive, using linear mixed effect modeling [function lmer (): lme 4 package in $\mathrm{R}$, version 3.6.3].

Based on model comparisons, using the Akaike Information Criterion, the final model (Table 5) included the fixed factors WM LOAD and BLOCK. We also included random intercepts for participants, items, and by-participant random slopes for
BLOCK. The dependent variable was the response time in milliseconds (log-transformed).

The factor WM LOAD was not a significant predictor, showing that there was no difference in RTs between the no WM load condition and both the low WM load condition $(\beta=-0.086 ; t=$ $-1.120 ; p=0.270)$ and the high WM load condition $(\beta=-0.099$; $t=-1.283$; $p=0.207)$. A releveled model with the low WM load condition as the reference level showed that there was no difference between the low and high WM load conditions either $(\beta=-0.01 ; t=-0.273 ; p=0.708)$. These findings are different from the findings by De Neys and Schaeken (2007), who found that pragmatic interpretations under a high load took longer than pragmatic interpretations in the low-load condition. Although not significant, in our model, the estimates of the factor WM LOAD were negative, suggesting that participants became faster under a WM load. This is the opposite direction as the results found by De Neys and Schaeken (2007) where the participants became slower. One reason may be the differences between the tasks. De Neys and Schaeken (2007) used a dot-pattern task, which might have been easier than our digit-span recall task. In our task, the participants may attempt to decrease the WM load by speeding up their responses, thus reducing the period of time during which they need to remember the digits.

The final model did include a main effect of the factor BLOCK $(\beta=-0.155 ; t=-4.946 ; p<0.001)$, again showing that the participants' response times were lower in block 2 , probably as a result of task experience.

\section{Response Times in Condition Each-Collective}

To check for a difference in RTs within condition EachCollective, we analyzed the log-transformed RTs of condition Each-Collective, using linear mixed effect modeling [function lmer (): lme 4 package in $\mathrm{R}$, version 3.6.3]. We included the factor RESPONSE, separating the RTs of the "no" responses from the "yes" responses to be able to find out whether there is a difference in RTs between the different response types, like we found in condition The-Distributive.

Based on step-wise model comparisons, using the Akaike Information Criterion, the final model (Table 6) included the fixed factors RESPONSE, WM LOAD, and BLOCK. We also included random intercepts for the participants, items, and by-participant random slopes for RESPONSE and BLOCK. The dependent variable was the response time in milliseconds (log-transformed).

Although the final model based on model comparisons included a three-way interaction between the factors RESPONSE, WM LOAD, and BLOCK, we only found a main effect of BLOCK $(\beta=-0.185 ; t=-4.313 ; p<0.001)$ and an interaction between RESPONSE and BLOCK $(\beta=0.258 ; t=3.380 ; p<0.001)$. Crucially, the factor RESPONSE did not turn out to be significant, showing that there was no difference in RTs between "yes" and "no" responses in condition Each-Collective. The participants reacted similarly to "no" responses as to "yes" responses. This is in contrast with response latencies in the The-Distributive condition, where we did find a difference between the response types. The difference in response times between conditions TheDistributive and Each-Collective points to a different process underlying the interpretations of the items in both conditions. 


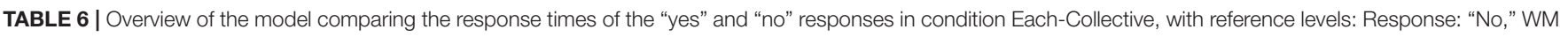
Load: "No Load," and Block: 1.

\begin{tabular}{|c|c|c|c|c|c|}
\hline Predictors & Estimate $(\beta)$ & SE & df & $t$ & $p$ \\
\hline Intercept & 8.148 & 0.047 & 41 & 171.948 & $<0.001$ \\
\hline Response "Yes" & -0.044 & 0.058 & 34 & -0.747 & 0.460 \\
\hline WM load low & -0.103 & 0.066 & 38 & -1.558 & 0.012 \\
\hline WM load high & -0.086 & 0.071 & 38 & -1.212 & 0.233 \\
\hline Block 2 & -0.185 & 0.043 & 65 & -4.313 & $<0.001$ \\
\hline Response "Yes" × WM Load low & -0.090 & 0.081 & 37 & -1.124 & 0.269 \\
\hline Response "Yes" × WM Load high & -0.057 & 0.085 & 40 & -0.672 & 0.505 \\
\hline Response "Yes" × Block 2 & 0.258 & 0.076 & 151 & 3.380 & $<0.001$ \\
\hline WM Load low × Block 2 & 0.090 & 0.084 & 74 & 1.070 & 0.288 \\
\hline WM Load high × Block 2 & 0.033 & 0.085 & 79 & 0.387 & 0.700 \\
\hline Response "Yes" × WM load low $\times$ Block 2 & -0.118 & 0.117 & 99 & -1.009 & 0.316 \\
\hline Response "Yes" $\times$ WM load high $\times$ Block 2 & -0.147 & 0.118 & 102 & -1.247 & 0.215 \\
\hline
\end{tabular}

\section{DISCUSSION}

In the present study, we investigated whether the adult preference for collective interpretations for distributively unmarked sentences with plural NPs requires working memory resources. We found an effect of loading WM on interpretation preferences.

The-Distributive items were accepted $41 \%$ of the time in the No WM load group, a rate comparable to previous adult findings [de Koster et al. (2017) for Dutch; Pagliarini et al. (2012) for Italian]. Crucially, when WM was loaded, participants accepted items of condition The-Distributive at a significantly higher rate $(80 \%$ for the low WM load condition and $78 \%$ for the high WM load condition). These general results are as predicted by the implicature account of distributivity preferences (Dotlačil, 2010). Loading adults' WM elicits a higher rate of acceptance for the TheDistributive condition, that is, the condition argued to involve an implicature.

In the rest of the discussion, we focus on three main issues in interpreting our results. First, we did not find a difference between high and low WM loads, only between the no load and load conditions. Does this matter? And what might explain this result? Second, we unexpectedly found an increase in acceptance for the Each-Collective items in the WM load conditions. What could explain this result? And is there evidence that distinguishes it from the increase in acceptance for the The-Distributive items? Finally, a major advantage of the implicature account compared to other explanations for collective and distributive preferences is that it offers an explanation for children's non-adult preferences, since children are known to be less likely to calculate implicatures. But can our results plausibly explain children's very late acquisition of adult preferences?

\section{Different Load Conditions Effects}

Contrary to our expectations, we did not find a difference between the low WM load condition and the high WM load condition. We only found a difference between the two WM load conditions on the one hand the no WM load condition on the other hand. Adults showed greater acceptance of distributive readings without distributive marking in both WM load conditions compared to the no WM load condition.

Similar results have actually been found in another study. van Tiel et al. (2019), who treated no WM load, low WM load, and high WM load, all as between subject conditions, also found a difference between the no load condition and the load conditions for some-not all. Note, however, that the other dual task studies that tested only the some-not all implicature (De Neys and Schaeken, 2007; Dieussaert et al., 2011; Marty and Chemla, 2013, Marty et al., 2013) did not include a no WM load condition, so we cannot be sure whether or not they might have found a difference between a no load and the low load condition.

There is also some evidence that different implicatures show different sensitivities to cognitive load. We know from previous studies that, even without a cognitive load, implicatures vary in rates of calculation (see, e.g., van Tiel et al., 2016; Sun, 2018). In our study, the low WM load condition was already sufficient to lead to more acceptance of The-Distributive items, and this may be because the proposed scale maybe less common or less automatized than the <some, all > scale. In fact, van Tiel et al. (2019) also found that different implicature types showed varying degrees of sensitivity (or lack of) to WM load. It could be that the less frequent or familiar a scale is, the more sensitive that a scale will be to working memory limitations.

Another factor that may have influenced the effect found was our choice of secondary task. Most other dual-task studies cited [except for Marty et al. (2013) that used backwards letter sequence retrieval, and Ryzhova and Demberg (2020) that used a dot-tracking task] used the dot memory task, where participants had to either recall a very simple dot-matrix pattern of three dots in a vertical or horizontal row, or a more complex pattern of four dots. While the four-dot matrix pattern has been shown to tap executive working memory (see e.g., Miyake et al., 2001) it is not clear to what degree the simpler three-dot matrix pattern actually requires WM resources. In comparison with this three-dot matrix pattern task, our three-digit memory task may load working memory more than the three-dot matrix patterns. Further investigations are needed to know to what degree these different secondary tasks load working memory. 
There are, however, two issues we should discuss related to our No WM load group. The number of participants in our noload group was relatively small (namely, 16, compared with 58 in the load group). While the response rates to the four different conditions tested in the No WM load group are similar to what we have found in previous experiments with adults, using the same visual materials (e.g., de Koster et al., 2018), it is well-known from the implicature literature that the rate of implicature can vary widely, that individuals also may differ in their tendency to calculate implicatures (see, e.g., Feeney and Bonnefon, 2013), and that this can be affected by, e.g., individual differences in working memory capacity (Dieussaert et al., 2011). Despite the large effect size, we have to be cautious about interpreting this comparison, because it could be that our No WM load group was made up of individuals who were particularly predisposed to calculate the implicature, which, in turn, could have made the comparison with the load group particularly significant.

The second issue is that, while the no-load group and load groups were between subjects, the two load groups were within subjects. A stronger comparison could be made if all conditions were run within the participants. However, there are also two problems with doing so. First, the experiment with two conditions was already quite long: Running our two load conditions within the participants already took $\sim 1 \mathrm{~h}$, so running all three conditions as a between-participants study might introduce practice and fatigue effects. Second, exposure to so many items might also lead to unwanted influences and make comparisons between reaction times less valid. This is one of the reasons why van Tiel et al. (2019) ran all three load conditions between subjects. Future work should carefully consider these design issues.

\section{Each-Collective Items More Acceptable Under WM Load}

An unexpected result of our experiment was that, under WM load, adults increased their acceptance of Each-Collective items as well. The effect size is smaller than the increase in the acceptance rate of The-Distributive items (which doubled from $40 \%$ to around $80 \%$ ), but it was still substantial and significant (from $32 \%$ to $57 \%$ ).

In fact, given the literature on quantifiers, which suggests that distributive marking is semantically incompatible with most collective situations, the acceptance rate of $32 \%$ for Each-Collective items is actually unexpected. However, our experiments were run in Dutch, and Dutch elke has been shown to be closer in interpretation to English every than to English each. Several experimental studies on Dutch have shown that, while participants strongly prefer distributive meanings with Dutch elke in a preference task, they will accept a collective interpretation with elke in a picture verification task at relatively high rates (around 35\%), contrasting sharply with results with English each (Rouweler and Hollebrandse, 2015; de Koster et al., 2017). If Dutch elke is better understood as being, in some cases, compatible with both distributive and collective interpretations but with a bias to a distributive interpretation, then one explanation for the effect of WM load may be that the ambiguity resolution process is affected by limited WM capacity, leading some participants to simply abandon disambiguation and simply accept all presented situations with elke. Thus, this finding could be similar to the finding of van Rij et al., 2013 that the resolution of ambiguous pronouns is affected by limited WM capacity due to the listener's decreased ability to integrate contextual information needed for the disambiguation.

Note, however, that this explanation is not simply a proposal that a WM load leads to greater acceptance across the board. Instead, the idea is that ambiguity resolution, specifically, may be more sensitive to WM capacity. Recall that participants were not more likely to accept interpretations in general under a WM load, and, for the false task control items, there was no difference in acceptance between the No WM load group and the WM load groups.

Additionally, the RTs for conditions The-Distributive and Each-Collective point to different underlying interpretation processes. Recall that we found out that "no" (pragmatic) responses for The-Distributive items were significantly slower than "yes" (literal) responses. Similar findings have been found in several studies of some-not all implicatures, including Bott and Noveck (2004), who found that rejecting upper-bound readings with some took longer than the literal, semantic interpretation. If the rejection of distributive readings with unmarked sentences is due to an implicature, it would be consistent with these other results, suggesting implicature calculation also takes longer. However, we did not find any difference in RTs between "yes" and "no" responses for the Each-Collective condition, suggesting that the increased acceptance rate under a WM load is due to a different underlying process more than the increased acceptance found with The-Distributive.

\section{Children's Non-adult Preferences and the Role of WM}

The implicature account of distributive preferences argues that children fail to interpret distributively unmarked sentences as collective because they fail to calculate the implicature. Young children's lower working memory capacity is often used to explain their failure to compute implicatures, so does finding a role for working memory in distributivity preferences offer an explanation for children's late acquisition?

Studies of implicature acquisition for different scales have often found gaps of several years between when children have the lexical knowledge required for an implicature and when they actually compute the implicature. Even for the well-studied some-not all implicature, acquisition results seem to suggest that children at age 4 already possess the lexical knowledge necessary for implicature calculation, but many studies find that they do not calculate implicatures consistently until around age seven (e.g., Noveck, 2001; Pouscoulous et al., 2007; Foppolo et al., 2012). Furthermore, previous findings indicate that different implicatures are acquired at different ages. Noveck (2001), for example, examined implicatures based on the $<$ might, must $>$ scale in which the modal might implies that the stronger must does not hold. He found out that 7-year-olds were the youngest 
to demonstrate modal competence overall, but that 7- and 9year-olds still interpreted might logically (not implicating "not must") more often than adults did. This shows that 9-year-old children did not fully master the might-not must implicature, yet, though presumably, they already had the lexical knowledge and working memory capacity at age 9 to calculate the somenot all implicature. For distributivity, children are non-adult-like in their distributivity preferences until comparatively late. Recall that Dutch children at age 11 were still not adult-like (de Koster et al., 2018) and Italian children at age 14 were also not adultlike (Pagliarini et al., 2012). However, experimental research has shown that, by age nine, children know that lexically distributive markers signal distributivity. At this age, we would expect that children have sufficient working memory capacity for the implicature calculations needed. With such a large gap between acquisition of the lexical scale and adult-like performance in the calculation of the proposed implicature, the role of working memory in the acquisition process is unclear.

One possibility is that working memory capacity is not really the bottleneck in children's late development of collective interpretation preferences. The difficulty is not in the decision to calculate the implicature, or the comparison of alternatives (which may require memory resources) but in recognizing collective and distributive interpretations as comparable alternatives on an informativity scale. Children may need much more verbal experience than what they have at age 9 (or age 11-14) and need to encounter many more examples where the distinction is relevant before they will begin to interpret the two meanings and their potential marking as alternatives on a scale. While many expressions satisfy the requirements to create a scale, only in a context in which the contrast is relevant do implicatures arise. Thus, $<$ car, Honda civic $>$ is a scale, but if a speaker said that a car almost hit them on their morning bike ride, this is unlikely to give rise to the implicature that the car was not a Honda civic, because, in that context, the specific make of the car is irrelevant [see Matsumoto (1995) and Geurts (2010) for more discussion of the contextual constraints on implicatures]. But this also means that, in addition to the recognition of the scale, experience with a weaker term being used in contexts where the contrast with the stronger is relevant is also important, and, for some scales, this might not be all that frequent. Even some-not all implicatures, which many researchers believe to be so frequent as to be (almost) a default interpretation, have been found in corpus studies to be much less frequent than previous believed [e.g., see Degen (2015) and Eiteljoerge et al. (2018), who found that only about $15 \%$ of uses of some in child-directed speech were intended with an implicature meaning]. An additional difficulty could be that, unlike many other scales, the expressions the and each require different inflectional morphology (e.g., each requires a singular verb, and plural definite descriptions require plural verbal morphology in English and in Dutch) and cannot simply be substituted for each other. Even though it is known that substitutability is not a requirement for scalar expressions [e.g., because it does not work in many contexts, e.g., downward entailing environments, see Geurts (2010) for a discussion], it still may influence how easy it is to acquire the scale and associated implicatures. If frequency and experience, indeed, explain children's late acquisition of adult-like preferences, then the lower rate of implicature in adults in our study and children in other studies has different origins: Adults under a working memory load do not calculate the implicature because it requires too many resources. Children do not calculate the implicature because they do not have sufficient experience with the competing alternatives until quite late. The gradual acquisition that we see in children from age nine onwards could then be reflective of a gradual increase in an experience that translates into greater awareness of the scale and thus a greater tendency to recognize the contrast and calculate the implicature.

The alternative explanation is that working memory capacity still does play a role in children's development, and that greater WM capacities, in combination with greater experience, only comes together quite late (e.g., 14+). The advantage of this proposal is that it offers an explanation for the correlation found between working memory and the rate of implicature calculation in de Koster et al. (2017), a relationship that would otherwise be hard to explain if working memory does not play a role at all in children's interpretation processes. More research can, perhaps, help distinguish between these two possible explanations.

\section{CONCLUSIONS AND DIRECTIONS FOR FUTURE RESEARCH}

Summarizing, we found that loading adults' WM leads them to accept distributive interpretations without distributive marking, a result that is predicted by the theoretical proposal that adult collective preferences for distributively unmarked sentences originate from a pragmatic implicature. This study thus makes a novel contribution to our understanding of the semantic and pragmatic processes underlying distributivity and their interaction with cognitive resources such as working memory.

Many open questions remain. First, in general, we need more studies looking at other proposed quantity implicatures. Most research has focused on the <some, all $>$ scale and, to a certain degree, the <or, and $>$ scale, but, within the research that has examined the processing of other proposed scales, it does seem that implicatures differ widely in their tendency to be calculated, and their tendency to be sensitive to processing limitations. But we need to confirm this variation experimentally. Second, for distributivity preferences, in particular, it still remains unclear what role working memory capacity plays in children's non-adult interpretation preferences. While working memory capacity was shown to correlate with the rejection of distributive readings without distributive marking in children (de Koster et al., 2018), the very late age at which children begin to be adult-like in their interpretation preferences suggests that other factors, such as experience with the scale or with distributive and collective situations, might play an even bigger role. Investigating this further would help clarify children's development. Another issue is the question of where working memory resources actually come into play in interpretation. Studies such as Marty and Chemla (2013) have found some evidence suggesting that the decision to calculate an implicature may be what requires cognitive resources, 
but more studies are needed. Future research should develop experiments to try to pinpoint where in the interpretation process resources are required. With more experimental investigations, we can hopefully develop a fuller picture of distributive interpretation preferences.

\section{DATA AVAILABILITY STATEMENT}

The raw data supporting the conclusions of this article will be made available by the authors, without undue reservation.

\section{ETHICS STATEMENT}

The study in this article, which involves human participants, was reviewed and approved by the Research Ethics Committee (CETO) of the University of Groningen. The participants provided their written informed consent to participate in this study.

\section{REFERENCES}

Akaike, H. (2011). “Akaike's information criterion," in International Encyclopedia of Statistical Science, ed M. Lovric (Berlin; Heidelberg: Springer). doi: 10.1007/978-3-642-04898-2_110

Avrutin, S., and Thornton, R. (1994). Distributivity and binding in child grammar. Lingu. Inquiry. 25, 165-171.

Baayen, R. H., Davidson, D. J., and Bates, D. M. (2008). Mixed-effects modeling with crossed random effects for subjects and items. J. Mem. Langu. 59, 390-412. doi: 10.1016/j.jml.2007.12.005

Banga, A., Heutinck, I., Berends, S. M., and Hendriks, P. (2009). "Some implicatures reveal semantic differences," in Linguistics in the Netherlands, eds B. Botma and J. van Kampen (Amsterdam: John Benjamins), 1-13. doi: 10.1075/avt.26.02ban

Bott, L., Bailey, T. M., and Grodner, D. (2012). Distinguishing speed from accuracy in scalar implicatures. J. Mem. Lang. 66, 123-142. doi: 10.1016/j.jml.2011.09.005

Bott, L., and Noveck, I. A. (2004). Some utterances are underinformative: the onset and time course of scalar inferences. J. Mem. Lang. 51, 437-457. doi: 10.1016/j.jml.2004.05.006

Breheny, R., Katsos, N., and Williams, J. (2006). Are generalised scalar implicatures generated by default? An on-line investigation into the role of context in generating pragmatic inferences. Cognition 100, 434-463. doi: 10.1016/j.cognition.2005.07.003

Broekhuis, H., and den Dikken, M. (2012). Syntax of Dutch: Nouns and Noun Phrases. Vol. 2. Amsterdam: Amsterdam University Press. doi: 10.1017/9789048517602

Brooks, P. J., and Braine, M. D. S. (1996). What do children know about the universal quantifiers all and each? Cognition 60, 235-268. doi: 10.1016/0010-0277(96)00712-3

Burnham, K. P., and Anderson, D. R. (2002). A Practical InformationTheoretic Approach. Model Selection and Multimodel Inference, 2nd ed. New York: Springer.

Chambers, J. M., Cleveland, W. S., Kleiner, B., and Tukey, P. A. (1983). Graphical Methods for Data Analysis. Pacific Grove, CA: Wadsworth \& Brooks/Cole, 158-162.

Champollion, L. (2017). Parts of a Whole: Distributivity as a Bridge Between Aspect and Measurement. Vol. 66. Oxford: Oxford University Press. doi: $10.1093 /$ oso/9780198755128.003.0008

Chemla, E., and Bott, L. (2013). Processing presuppositions: Dynamic semantics vs pragmatic enrichment. Lang. Cogn. Processes. 28, 241-260. doi: 10.1080/01690965.2011.615221

\section{AUTHOR CONTRIBUTIONS}

$\mathrm{AK}$, JS, and PH conceived the experiment, analyzed the results, read, commented, and revised the manuscript. AK carried out the experiment and wrote the first draft of the manuscript. All the authors approved the final version of the manuscript.

\section{FUNDING}

This research was supported by a grant from the Netherlands Organization for Scientific Research (NWO) (Grant No. 322-75-010).

\section{SUPPLEMENTARY MATERIAL}

The Supplementary Material for this article can be found online at: https://www.frontiersin.org/articles/10.3389/fpsyg. 2021.556120/full\#supplementary-material

Chemla, E., and Singh, R. (2014). Remarks on the experimental turn in the study of scalar implicature, Part 1. Langu. Lingu. Compass 8/9, 373-386. doi: $10.1111 / \operatorname{lnc} 3.12081$

Chierchia, G. (2004). Scalar implicatures, polarity phenomena, and the syntax/pragmatics interface. Struct. Beyond 3, 39-103.

Chierchia, G. (2006). Broaden your views: Implicatures of domain widening and the "logicality" of language. Linguist. Inq. 37, 535-590. doi: 10.1162/ling.2006.37.4.535

Cremers, A., and Chemla, E. (2014). "Direct and indirect scalar implicatures share the same processing signature," in Pragmatics, Semantics and the Case of Scalar Implicatures, ed S. Pistoia Reda (London: Palgrave Macmillan), 201-227. doi: $10.1057 / 9781137333285 \_8$

de Hoop, H., and Kas,. M. (1989). Sommige betekenisaspecten van enkele kwantoren, oftewel: enkele betekenisaspecten van sommige kwantoren. Interdisc. Taal \&Tekstwetenschap. 9, 31-49.

de Koster, A. M. B., Dotlačil, J., and Spenader, J. K. (2017). "Children's understanding of distributivity and adjectives of comparison," in Proceedings of the 41st Annual Boston University Conference on Language Development, eds M. LaMendola and J. Scott (Cascadilla Press), 373-386.

de Koster, A. M. B., Spenader, J. K., Dotlačil, J., and Hendriks, P. (2020). “A multiple cue analysis of collective interpretations with 'Each,' in Proceedings of the 44th Annual Boston University Conference on Language Development, eds M. M. Brown and A. Kohut (Cascadilla Press), 252-265.

de Koster, A. M. B., Spenader, J. K., and Hendriks, P. (2018). "Are Children's Overly Distributive Interpretations and Spreading Errors Related?” in Proceedings of the 42nd Annual Boston University Conference on Language Development, eds A. B. Bertolini and M. J. Kaplan (Cascadilla Press), 413-426.

De Neys, W., and Schaeken, W. (2007). When people are more logical under cognitive load: Dual task impact on scalar implicature. Exp. Psych. 54, 128-133. doi: $10.1027 / 1618-3169.54 .2 .128$

Degen, J. (2015). Investigating the distribution of some (but not all) implicatures using corpora and web-based methods. Sem. Pragm. 8, 11-11. doi: $10.3765 /$ sp. 8.11

Degen, J., and Tanenhaus, M. K. (2016). Availability of alternatives and the processing of scalar implicatures: a visual world eye-tracking study. Cogn. Sci. 40, 172-201. doi: 10.1111/cogs.12227

Dieussaert, K., Verkerk, S., Gillard, E., and Schaeken, W. (2011). Some effort for some: further evidence that scalar implicatures are effortful. Q. J. Exp. Psych. 64, 2352-2367. doi: 10.1080/17470218.2011.588799

Dotlačil, J. (2010). Anaphora and distributivity: a study of same, different, reciprocals and others (Doctoral dissertation). Utrecht University, Netherlands. 
Dotlačil, J., and Brasoveanu, A. (2021). The representation and processing of distributivity and collectivity: ambiguity vs. underspecification. Glossa J. Gen. Linguist. 6:6. doi: 10.5334/gjgl.1131

Eiteljoerge, S. F., Pouscoulous, N., and Lieven, E. V. (2018). Some pieces are missing: implicature production in children. Front. Psych. 9:1928. doi: 10.3389/fpsyg.2018.01928

Feeney, A., and Bonnefon, J. F. (2013). Politeness and honesty contribute additively to the interpretation of scalar expressions. J. Lang. Soc. Psychol. 32, 181-190.

Foppolo, F., Guasti, M. T., and Chierchia, G. (2012). Scalar implicatures in child language: Give children a chance. Language learning and development. 8, 365-394. doi: 10.1080/15475441.2011.626386

Frazier, L., Pacht, J. M., and Rayner, K. (1999). Taking on semantic commitments, II: collective versus distributive readings. Cognition 70, 87-104. doi: 10.1016/S0010-0277(99)00002-5

Geurts, B. (2010). Quantity Implicatures. Cambridge: Cambridge University Press. doi: $10.1017 /$ СBO9780511975158

Gil, D. (1982). Quantifier scope, linguistic variation, and natural language semantics. Lingu. Philos. 5, 421-472. doi: 10.1007/BF00355582

Grice, H. P. (1975). "Logic and conversation," in Syntax and Semantics, Vol. 3: speech acts, eds P. Cole and J. J. Morgan (New York, NY: Academic Press), $41-58$.

Grodner, D. J., Klein, N. M., and Carbary, K. M., and Tanenhaus, M. K. (2010). "some," and possibly all, scalar inferencesare not delayed: evidence for immediate pragmatic enrichment. Cognition 116, 42-55. doi: 10.1016/j.cognition.2010.03.014

Hartshorne, J. K., and Snedeker, J. (2014). The speed of inference: evidence against rapid use of context in calculation of scalar implicatures (Manuscript submitted for publication).

Horn, L. R. (1973). On the semantic properties of logical operators in English (Doctoral dissertation). University of California, United States.

Horn, L. R. (1989). A Natural History of Negation. Chicago, IL: University of Chicago Press.

Huang, Y. T., and Snedeker, J. (2009). Online interpretation of scalar quantifiers: Insight into the semantics-pragmatics interface. Cogn. Psych. 58, 376-415. doi: 10.1016/j.cogpsych.2008.09.001

Huang, Y. T., and Snedeker, J. (2011). Cascading activation across levels of representation in children's lexical processing. J. Child Lang. 38, 644-661.

Kaup, B., Kelter, S., and Habel, C. (2002). Representing referents of plural expressions and resolving plural anaphors. Lang. Cogn. Processes. 17, 405-450. doi: $10.1080 / 01690960143000272$

Ko, V., Wieling, M., Wit, E., Nerbonne, J., and Krijnen, W. (2014). Social, geographical, and lexical influences on Dutch dialect pronunciations. Comput. Ling. Netherl. J. 4, 29-38.

Kursat, L., and Degen, J. (2020). "Probability and processing speed of scalar inferences is context-dependent," in Proceedings of the 42nd Annual Conference of the Cognitive Science Society, 1236-1242.

Landman, F. (2000). Events and Plurality: The Jerusalem Lectures. Vol. 76. Boston, MA: Kluwer Academic Pub. 10, 978-994. doi: 10.1007/978-94-0114359-2

Maldonado, M., Chemla, E., and Spector, B. (2019). Revealing abstract semantic mechanisms through priming: the distributive/collective contrast. Cognition 182, 171-176. doi: 10.1016/j.cognition.2018.09.009

Marty, P., Chemla, E., and Spector, B. (2013). Interpreting numerals and scalar items under memory load. Lingua, 133: 152-163. doi: 10.1016/j.lingua.2013.03.006

Marty, P. P., and Chemla, E. (2013). Scalar implicatures: working memory and a comparison with only. Front. Psych. 4:403. doi: 10.3389/fpsyg.2013.00403

Matsumoto, Y. (1995). The conversational condition on horn scales. Linguis. Philos. 18, 21-60. doi: 10.1007/BF00984960

Miyake, A., Friedman, N. P., Rettinger, D. A., Shah, P., and Hegarty, M. (2001). How are visuospatial working memory, executive functioning, and spatial abilities related? A latent-variable analysis. J. Exp. Psychol. Gen. 130, 621-640. doi: 10.1037/0096-3445.130.4.621

Miyamoto, Y., and Crain, S. (1991). Children's interpretation of plural pronouns: collective vs. distributive interpretation," in Proceedings of the Annual Boston University Conference on Language Development (Cascadilla Press).

Noveck, I. A. (2001). When children are more logical than adults: Experimental investigations of scalar implicature. Cognition. 78, 165-188. doi: 10.1016/S0010-0277(00)00114-1
Padilla-Reyes, R. E. (2018). Connections among scales, plurality, and intensionality in Spanish. (Doctoral dissertation). The Ohio State University, Ohio.

Pagliarini, E., Fiorin, G., and Dotlačil, J. (2012). "The acquisition of distributivity in pluralities, in Proceedings of the 36st Annual Boston University Conference on Language Development (Cascadilla Press), 2, 387-399.

Politzer-Ahles, S., and Fiorentino, R. (2013). The realization of scalar inferences: context sensitivity without processing cost. PLOS ONE 8:e63943. doi: 10.1371/journal.pone.0063943

Politzer-Ahles, S., and Husband, E. M. (2018). Eye movement evidence for context-sensitive derivation of scalar inferences. Collabra Psychol. 4, 1-13. doi: $10.1525 /$ collabra. 100

Pouscoulous, N., Noveck, I. A., Politzer, G., and Bastide, A. (2007). A developmental investigation of processing costs in implicature production. Lang. Acqu. 14, 347-375. doi: 10.1080/10489220701600457

Romoli, J., and Schwarz, F. (2015). "An experimental comparison between presuppositions and indirect scalar implicatures," in Experimental Perspectives on Presuppositions, ed F. Schwarz (Cham: Springer), 215-240. doi: 10.1007/978-3-319-07980-6_10

Rouweler, L., and Hollebrandse, B. (2015). Distributive, collective and "everything" in between: Interpretation of universal quantifiers in child and adult language. Lingu. Netherlands. 32, 130-141. doi: 10.1075/avt.32.10rou

Ryzhova, M., and Demberg, V. (2020). "Processing particularized pragmatic inferences under load," in Proceedings of the 42nd Annual Meeting of the Cognitive Science Society (CogSci 2020).

Spenader, J., and Bosnic, A. (2018). "Distributivity preferences for Dutch quantifiers elk and ieder." in Chapter in Hollebrandse, Vol. 41, eds B. Kim, J., Perez-Leroux, A. T., and Schulz, P. T.O.M. and Grammar: Thoughts on Mind and Grammar: A Festschrift in honor of Tom Roeper (Amherst, MA: Graduate Linguistics Student Association), 159-168.

Sun, C. (2018). Scalar implicature: gricean reasoning and local enrichment. (Doctoral dissertation). UCL (University College London)), London.

Syrett, K., and Musolino, J. (2013). Collectivity, distributivity, and the interpretation of plural numerical expressions in child and adult language. Lang. Acqu. 20, 259-291. doi: 10.1080/10489223.2013.828060

Tomlinson, J., Bott, L., and Bailey, T. (2011). "Understanding literal meanings before pragmatic inference: Mouse-trajectories of scalar implicatures," in 4th Biennial Conference of Experimental Pragmatics, 2-4.

Tunstall, S. (1998). The interpretation of quantifiers: Semantics and processing (Doctoral dissertation). University of Massachusetts, Amherst.

van der Ziel, M. E. (2012). The acquisition of scope interpretation in dative constructions: explaining children's non-target like performance (Doctoral dissertation). Utrecht University, Netherland.

van Rij, J., Van Rijn, H., and Hendriks, P. (2013). How WM load influences linguistic processing in adults: a computational model of pronoun interpretation in discourse. Topics Cogn. Sci. 5, 564-580. doi: $10.1111 /$ tops.12029

van Tiel, B., Pankratz, E., and Sun, C. (2019). Scales and scalarity: Processing scalar inferences. J. Mem. Lang. 105, 93-107. doi: 10.1016/j.jml.2018.12.002

van Tiel, B., van Miltenburg, E., Zevakhina, N., and Geurts, B. (2016). Scalar diversity. J. Sem. 33, 137-175.

Wieling, M., Montemagni, S., Nerbonne, J., and Baayen, R. H. (2014). Lexical differences between Tuscan dialects and standard Italian: accounting for geographic and sociodemographic variation using generalized additive mixed modeling. Language 90, 669-692. doi: 10.1353/lan.2014.0064

Wieling, M., Nerbonne, J., and Baayen, R. H. (2011). Quantitative social dialectology: explaining linguistic variation geographically and socially. PLoS ONE 6:e23613. doi: 10.1371/journal.pone.0023613

Conflict of Interest: The authors declare that the research was conducted in the absence of any commercial or financial relationships that could be construed as a potential conflict of interest.

Copyright $\odot 2021$ de Koster, Hendriks and Spenader. This is an open-access article distributed under the terms of the Creative Commons Attribution License (CC BY). The use, distribution or reproduction in other forums is permitted, provided the original author(s) and the copyright owner(s) are credited and that the original publication in this journal is cited, in accordance with accepted academic practice. No use, distribution or reproduction is permitted which does not comply with these terms. 